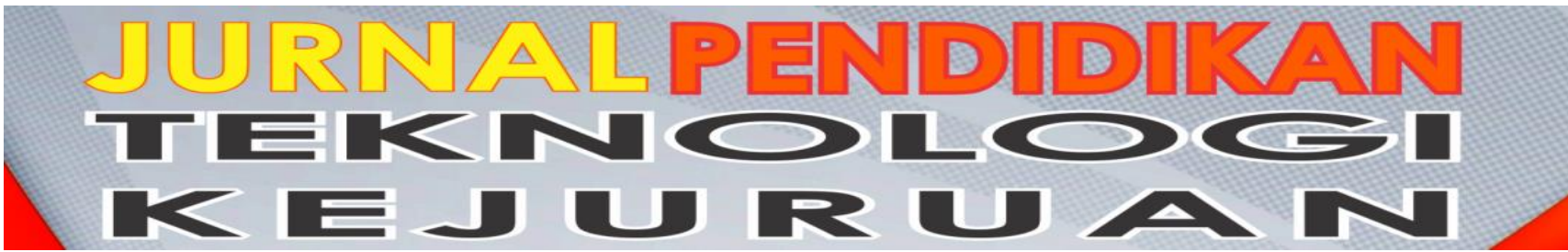

Vol. 4, No. 3 August 2021

P-ISSN: 2621-3273

E-ISSN: 2621-1548

\title{
Potensi Kompetensi Keahlian Baru di Bidang Game pada Tingkat SMK
}

\author{
Fardan Barkah Albari ${ }^{1}$, Muhammad Azhar Abulkhoir ${ }^{2}$, Nurul Khofifah Augustianingrum ${ }^{3 *}$ \\ Rizky Ananda ${ }^{4}$ \\ 1,2,3,4Pendidikan Multimedia, Universitas Pendidikan Indonesia \\ *Corresponding author, e-mail: nurulkhofifahaugustianingrum@upi.edu
}

\begin{abstract}
Vocational High School is a formal education that organizes vocational education at the senior secondary level which aims to prepare individuals to be ready for work. In this 4.0 industrial revolution, Indonesia needs a lot of human resources. The game industry has grown by 9-12\%. This shows that there is an opportunity in this gaming industry. The gaming industry is a mix of art and technology. Therefore, people who are skilled in the arts and technology are needed. This research method uses descriptive methods and qualitative analysis. Reported by CNBC (2019), Bekraf requires a digital workforce of around 600 thousand per year and this cannot be fulfilled. This shows the high demand from the digital industry. The survey results released by Bekraf show that the game industry is an industry that is aggressively innovating. There are also very many game enthusiasts in Indonesia. Game players from in Indonesia are ranked 16 in the world. In 2015, high school graduates or equivalent dominated the workforce in the creative industry, especially digital. This shows that SMK graduates have a great opportunity to develop the game industry in Indonesia.
\end{abstract}

Keyword: Vocational High School, Game Developer, Competence of Skill

Abstrak - Sekolah Menengah Kejuruan adalah salah satu bentuk pendidikan formal yang menyelenggarakan pendidikan kejuruan pada jenjang menengah atas yang bertujuan untuk menyiapkan individu untuk siap kerja. Pada revolusi industri 4.0 ini Indonesia memerlukan sumber daya manusia yang banyak. Pertumbuhan industri game mengalami pertumbuhan sebanyak 9-12\%. Ini menunjukan bahwa ada peluang dari industri game ini. Industri game adalah perpaduan dari seni dan teknologi. Oleh karena itu dibutuhkan orang yang terampil di bidang seni dan teknologi. Metode penelitian ini menggunakan metode deskriptif dan analisis kualitatif. Dilansir oleh CNBC (2019), Bekraf membutuhkan tenaga kerja digital sekitar 600 ribu pertahunnya dan belum bisa terpenuhi. Ini menunjukan adanya permintaan yang tinggi dari industri digital. Hasil survei yang dirilis oleh Bekraf bahwa industri game adalah industri yang gencar melakukan inovasi. Peminat game di Indonesia juga sangat banyak. Pemain game dari di Indonesia memiliki peringkat ke-16 di dunia. Pada tahun 2015, lulusan SMA sederajat mendominasi tenaga kerja di bidang ekonomi kreatif khususnya digital. Ini menunjukan bahwa lulusan SMK memiliki peluan besar untuk mengembangkan industri game di Indonesia.

Kata Kunci: SMK, Pengembang Game, Kompetensi Keahlian

\section{PENDAHULUAN}

Sekolah Menengah Kejuraan (SMK) merupakan salah satu bentuk satuan pendidikan formal yang menyelenggarakan pendidikan kejuruan pada jenjang pendidikan menengah sebagai lanjutan dari SMP/MTs. Berbeda dengan pendidikan umum, pendidikan kejuruan memiliki tujuan menyiapkan individu untuk siap bekerja. Sesuai dengan Permendikbud Nomor 10 tahun 2017, yaitu "Penyelenggaraan Sekolah Menengah Kejuruan (SMK) bertujuan untuk menyiapkan peserta didik memiliki keterampilah/keahlian di bidang tertentu agar siap memasuki dunia kerja sebagai tenaga kerja yg produktif dan mampu mengembangkan dirinya menciptakan lapangan kerja bagi dirinya sendiri melalui berwirausaha".

Berdasarkan pada tujuan tersebut maka hasil dari suatu proses penyelenggaraan pendidikan di Sekolah Menengah Kejuaruan (SMK) harus mampu memenuhi kebutuhan dunia kerja. Dengan demikian SMK harus mampu menjadi wadah yang dinamis dan adaptif agar mampu mengikuti perkembangan dunia industri pada tingkat lokal, nasional, dan global karena harus mengacu pada kebutuhan pasar kerja (demand driven) yang cenderung fluktuatif dan berubah-ubah sehingga sistem SMK sendiri seeperti 
"membidik sasaran yang bergerak" (Ace Suryadi, 2010).

Kebutuhan pasar kerja sendiri tentunya berbanding lurus dengan kebutuhan konsumen dan perkembangan ekomi yang terjadi. Dalam 1 dekade terakhir peningkatan yang signifikan terjadi adalah pada bidang teknologi seiring dengan pesatnya perkembangan teknologi diberbagai aspek kehidupan manusia. Salah satu dampaknya adalah pada industri yang mengakibatkan lahirnya gelombang Revolusi Industri 4.0, Lahirnya gelombang Revolusi Industri 4.0 ini mempengaruhi kebutuhan dunia kerja akan Sumber daya manusia yang diperlukan.

Sehingga pada aspek Pendidikan khusunya pendidikan kejuruan yang begitu dekat dengan dunia industri harus mengalami perubahan karena munculnya industri-industri baru atau meningkatnya kebutuhan pada suatu sektor industri tertentu. Salah satu industri yang berkembang dan banyak bermunculan adalah industri gim. Menurut data Asosiasi Game Indonesia (AGI) pada tahun 2020 terdata sebanyak 89 perusahaan gim baik yang berfokus pada pengembangan gim ataupun sebagai penerbit gim. Data tersebut didukung dengan data Kominfo mengenai pertumbuhan industri game yang pertahunnya mengalami pertumbuhan sebanyak 9-12 industri baru.

Melihat jumlah ketersediaan industri dan perkembangan industri yang terjadi, maka dapat dilihat adanya sebuah peluang kebutuhan pangsa kerja atau sumber daya manusia untuk memenuhi kebutuhan industri gim. Sedangkan Industri gim bukanlah industri perangkat lunak (O'Donnell dalam Maulana, 2020). Dengan demikian dapat dikatakan industri game merupakan industri yang unik dan spesial karena merupakan perpaduan antara seni dan teknologi. Oleh karena itu dibutuhkan sumber daya manusia yang terampil dan spesialis pada bidangnya karena sebenarnya industri ini berbeda dengan industri perangkat lunak, teknologi informatika atau sejenisnya sehingga dibutuhkan keterampilan lebih selain keterampilan perancangan perangkat lunak. Hal ini dapat dilihat dari pembagian kerja pada sebuah rumah industri game yang pada umumnya terdiri dari : Game Developer, Game 2D Artist, Game Designer, Project Manager, Game Producer, Animator, Game 3D Artist, Story Writer, Creative Director, Game Audio Engineering.

Melihat peluang yang ada pada ketersediaan dan perkembangan industri gim di Indonesia dengan ketersediaan suplay akan kebutuhan sumber daya manusianya, maka muncul suatu peluang lahirnya program keahlian baru pada Sekolah Menengah
Kejuruan (SMK) yang menyasar pemenuhan kebutuahn sumber daya manusia pada industri gim. Oleh karena itu tujuan penelitian kali ini, diantaranya:

1. Mengetahui proses pembentukan kompetensi keahlian baru

2. Mengetahui penyebaran dan wilayah industri gim

3. Mengetahui urgensi lahirnya kompetensi keahlian baru Sekolah Menengah Kejuraun (SMK) untuk pemenuhan kebutuhan sdm industri gim khususnya di wilayah potensial

\section{METODE}

Penelitian ini menggunakan metode deskriptif dengan analisis kualitatif, dimana data terkait pembentukan kompetensi keahlian SMK, serta penyebaran wilayah industri gim diuraikan guna mendapat gambaran yang sesuai dengan tujuan penelitan.

Melalui studi kepustakaan, data-data yang relevan dengan topik pembahasan dihimpun melalui berbagai macam sumber bacaan seperti ensklopedia, buku, jurnal, serta internet. Hasil data-data yang dikumpulkan akan saling dikaitkan dan dianalisis untuk memperoleh informasi penting mengenai urgensi lahirnya program keahlian Sekolah Menengah Kejuruan (SMK) baru dalam pemenuhan sdm industri gim serta data wilayah penyebaran industri gim.

\section{HASIL}

Seiring dengan dinamisnya dunia industri, juga revolusi industri 4.0. Dimana dalam revolusi industri 4.0 ini memiliki ciri yaitu teknologi yang mulai menyatu lekat dengan manusia, contohnya adalah robot, komputasi kuantum, bioteknologi, otomasi kendaraan, internet, sistem virtual dan fisik yang menjadi satu kesatuan, dsb. Profesi dan juga lapangan pekerjaan baru juga semakin bermunculan. Jenis pekerjaan baru yang berhubungan dengan dunia digital seperti ; pemasaran digital, kreator video, analis data, desainer tampilan antarmuka, dsb. Pekerjaan-pekerjaan baru yang berhubungan dengan digital ini sangat diminati dan berkembang pesat di Indonesia.

Dilansir oleh CNBC (2019), Badan Ekonomi Kreatif (Bekraf) sangat membutuhkan tenaga kerja digital sekitar 600 ribu orang pertahunnya dan masih belum bisa dipenuhi. Hal ini menunjukan demand atau permintaan besar dari industri digital tersebut perlu untuk ditangani serius oleh pemerintah Indonesia. Karena sektor industri digital ini menjadi peluang menjanjikan bagi Indonesia untuk meningkatkan perekonomian. Karena berdasarkan kepada survey yang dilakukan oleh Bekraf pada tahun 2015, sektor ekonomi kreatif berhasil menyumbangkan Produk Domestik Bruto (PDB) sebesar 852,24 triliun atau 
sekitar 7,38\% dari jumlah PDB Karena berdasarkan kepada survey yang dilakukan oleh Bekraf pada tahun 2015, sektor ekonomi kreatif berhasil menyumbangkan Produk Domestik Bruto (PDB) sebesar 852,24 triliun atau sekitar 7,38\% dari jumlah PDB

Dalam hal ini upaya untuk meningkatkan dan memenuhi kebutuhan tenaga kerja dapat dipasok dari beberapa sektor, salah satunya adalah sektor pendidikan. Dengan mendorong kepada penyelenggara pendidikan untuk meningkatkan kemampuan lulusan dan juga selalu mengikuti perkembangan dan kebutuhan industri, tentu hal ini akan berbanding lurus dengan keterserapan lulusan dari berbagai tingkatan atau jenjang pendidikan. Terutama pada pendidikan vokasi, baik tingkat sekolah menengah maupun tingkat pendidikan tinggi. Karena menurut (Bruri, 2017), sifat dari pendidikan vokasi harus menyesuaikan terhadap kebutuhan dunia kerja yang menyebabkan pendidikan vokasi harus lebih lentur dan harus cepat beradaptasi terhadap perubahan. Dalam menanggapi perubahan yang cukup pesat dalam dunia industri digital ini, pendidikan vokasi khususnya tingkat menengah melalui kemendikbud harus melakukan berbagai program yang mendukung kepada pengembangan bidang keahlian yang sesuai dengan perkembangan dunia industri. Dengan itu Presiden mengeluarkan INPRES No.9 tahun 2016 tentang revitalisasi SMK, sesuai instruksinya kepada Menteri Pendidikan dan Kebudayaan adalah untuk membuat peta pengembangan SMK dan meningkatkan link and match dengan dunia industri.

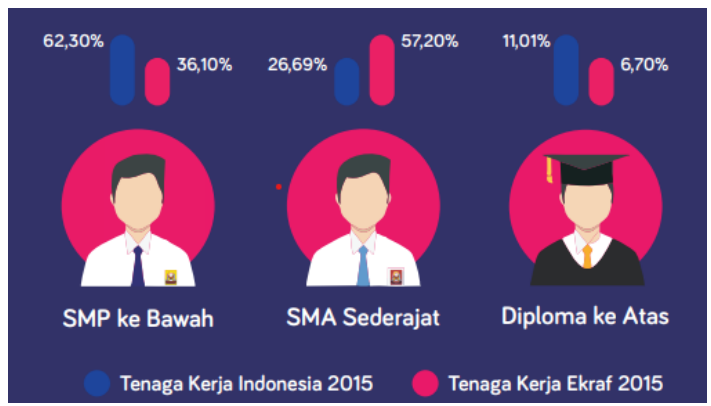

Gambar 1. Hasil Survei Khusus Ekonomi Kreatif

Tentu dapat dilihat dalam data survei yang dirilis oleh Badan Ekonomi Kreatif pada tahun 2017, menunjukan bahwa pada tahun 2015 status pendidikan tenaga kerja Indonesia pada masih tertinggi pada lulusan SMA sederajat. Dengan itu berarti keterserapan lulusan di bidang ekonomi kreatif khususnya digital lebih banyak adalah siswa SMA/SMK sederajat. Hal ini menjadikan lulusan SMK memiliki peluang yang besar untuk menjadi pemenuh dari kebutuhan tenaga kerja di industri digital Indonesia yang masih sangat kurang.

Pembentukan kompetensi keahlian baru di SMK sendiri memang memerlukan analisis mendalam mengenai Kegiatan Ekonomi Utama (KEU) setiap daerahnya. Karena menurut (Siswantari, 2015), keterserapan alumni SMK dalam bursa kerja berarti tercipta pendapatan bagi alumni SMK tersebut yang artinya akan mendorong kepada pendapatan Produk Domestik Regional Bruto (PDRB). Pembukaan dari kompetensi keahlian ini juga harus memerhatikan kepada spektrum keahlian pendidikan menengah kejuruan (Kemendikbud RI, 2016), kompetensi keahlian baru ini nantinya harus melalui berbagai tahapan yang akhirnya adalah penetapan pembukaan kompetensi keahlian baru dengan gambaran diagram proses sebagai berikut ;

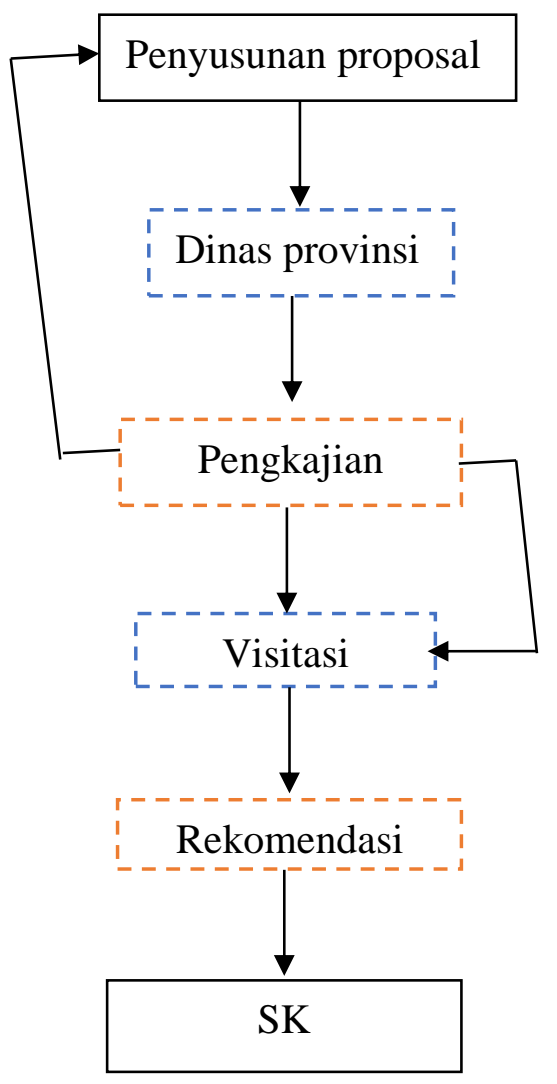

Gambar 2. Diagram Proses Pembentukan Kompetensi Keahlian Baru di SMK

\section{DISKUSI}

Pembentukan kompetensi keahlian baru di SMK ini juga dapat dijabarkan dalam bentuk tabel, dengan gambaran sebagai berikut; 


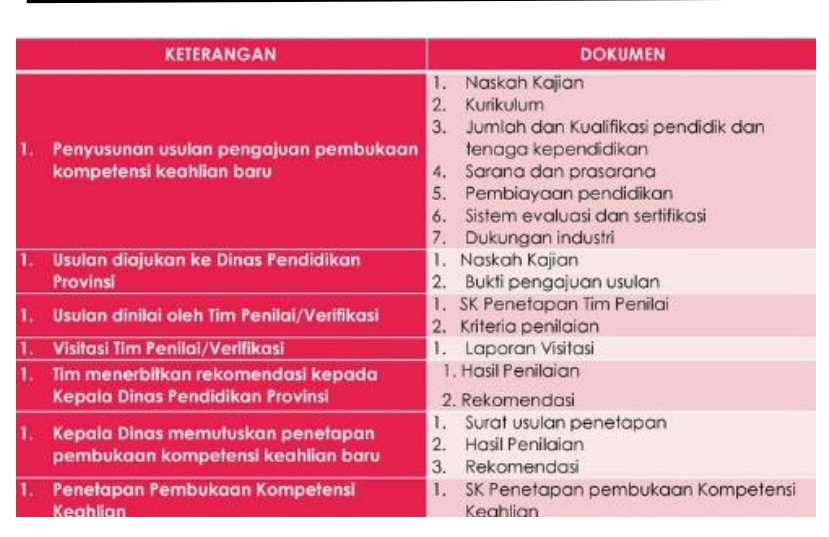

Gamber 3 Proses Pembukaan Kompetensi Keahlian Baru di SMK

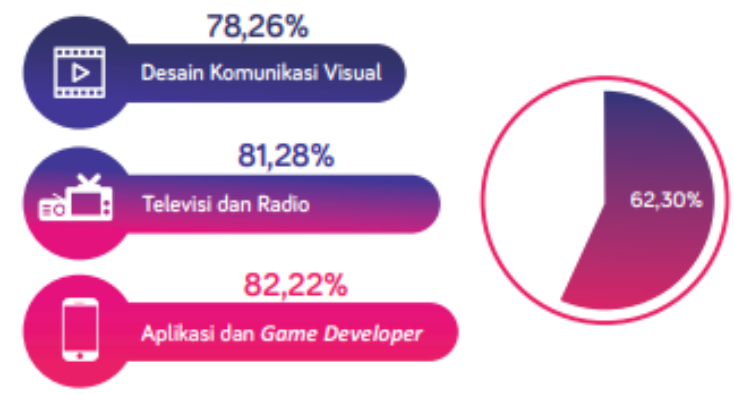

Gambar 4. Hasil Survei Khusus Ekonomi Kreatif

Hal yang menarik dalam hasil survei yang dirilis oleh Bekraf ini adalah pada industri bidang game developer, industri inilah yang paling gencar melakukan inovasi atau dalam statistiknya adalah sekitar $82,22 \%$. Karena tidak dapat dipungkiri jika peminat game di Indonesia cukup tinggi dan terus berkembang. Menurut data yang dilansir oleh lokadata, 2017 ada sekitar 43,7 juta pemain game daring di Indonesia. Mereka menyumbangkan pendapatan sekitar 880 juta dollar AS. Pemain game daring di Indonesia juga merupakan peringkat ke-16 di dunia.

Pasar yang sangat besar ini membuat banyak sekali lapangan pekerjaan dibutuhkan di bidang ini. Dalam bidang ini juga dapat dikembangkan beberapa pekerjaan yang nantinya disediakan oleh sebuah perusahaan yang mengelola bidang game ini. Trend dari pekerjaan di bidang start up atau perusahaan yang identik dengan digital ini cukup populer dikalangan generasi milenial. Hal ini karena persentase usia pekerja di bidang ini adalah usia 1524 sejumlah 17,8\% dan usia 25-59 tahun sejumlah 75,5\% (Badan Ekonomi Kreatif, 2017) .

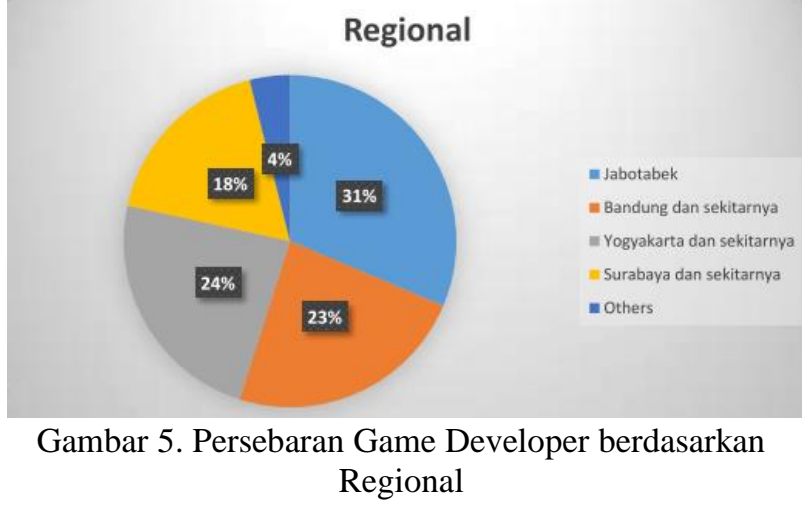

Berdasarkan data pemetaan industri game Indonesia tahun 2015 yang dirilis oleh (Kominfo, 2016), persebaran regional game developer di Indonesia paling banyak adalah di daerah Jabodetabek dengan persentase sebesar 31\% diatas Yogyakarta dan juga Bandung.

Ini menunjukkan bahwa jika mengacu kepada prinsip pembentukan kompetensi keahlian SMK yang telah dibahas sebelumnya, daerah-daerah tersebut dapat menjadi pertimbangan. Lalu melihat dari bidang pekerjaan ini adalah mengedepankan kepada keterampilan, maka penyelenggara pendidikan kejuruan tingkat sekolah menengah ini harus lebih memerhatikan kepada sertifikasi keahlian dan juga pelatihan yang sesuai dengan bidang yang digeluti. Proses standarisasi dan pembuatan kurikulum juga harus melibatkan perusahaan-perusahaan yang bergerak di bidang game agar terjadi simbiosis mutualisme. Jika lulusan SMK dapat sesuai dengan standar industri game tersebut maka kemungkinan keterserapan lulusan akan semakin besar dan nantinya akan berdampak kepada peningkatan ekonomi Indonesia.

\section{KESIMPULAN}

Pasar game di Indonesia sangat berkembang. Pemain game daring di Indonesia mendapat peringkat ke-16 dari seluruh dunia. Hal ini menunjukan bahwa pasar game di Indoensia memiliki peluang yang sangat besar terutama dalam lapangan perkejaan. Dengan besarnya pasar game di Indonesia menunjukan bahwa diperlukannya sumber daya manusia yang fokus untuk mengembangkan bidang game ini.

Dari data yang dirilis oleh Badan Ekonomi Kreatif tahun 2017 menunjukan bahwa pada tahun 2015 lulusan di bidang ekonomi kreatif khususnya digital lebih banyak adalah siswa SMA/SMK sederajat. Ini menunjukan bahwa lulusan SMK memiliki potensi besar untuk terjun ke industri digital yang di Indonesia sendiri kekurangan sumber daya manusia di bidang tersebut. Dengan adanya bidang keahlian 
game di SMK, diharapkan lulusan dari SMK tersebut dapat ikut serta mengembangkan industri game di Indonesia dan juga dapat mengembangkan ekonomi kreatif di Indonesia.

\section{DAFTAR PUSTAKA}

Maulana,A. (2020). Sosialisasi Riset Peta Industri Game Indonesia oleh Kominfo. LItbang, dan AGI. Sosialisasi Nasional. https://www.youtube.com/watch?v=Q5WxO$\mathrm{hFreY} \& \mathrm{t}=2638 \mathrm{~s}$

Badan Ekonomi Kreatif. (2017). Data Statistik dan Hasil Survei. In Hasil Survei Khusus Ekonomi Kreatif.

Bruri, M. T. (2017). Pendidikan vokasi yang berada di jalur berbeda dengan pendidikan jalur akademi . pada abad 18-19 melalui industri empat seperti yang tersebutkan di. Tantangan Revolusi Industri Ke 4 (i4.0) Bagi Pendidikan Vokasi, 4, 1-5.

Hastuti, R. K. (2019). Pak Jokowi, RI Kekurangan 600 Ribu SDM Digital per Tahun. Pak Jokowi, RI Kekurangan 600 Ribu SDM Digital per Tahun.

https://www.cnbcindonesia.com/tech/2019100 4141645-37-104482/pak-jokowi-rikekurangan-600-ribu-sdm-digital-per-tahun

Kemendikbud RI. (2016). Surat Keputusan Dirjen Dikdasmen Nomor 4678/d/kep/mk/2016.

Kominfo, D. P. I. I. (2016). Peta Industri Game Indonesia tahun 2015.

lokadata. (2017). Pemain game online di Indonesia menurut usia. lokadata.id. https://lokadata.beritagar.id/chart/preview/pem ain-game-online-di-indonesia-menurut-usia2017-1555167552

Permendikbud. (2017). Peraturan Menteri Pendidikan dan Kebudayaan Republik Indonesia Nomor 10 tahun 2017 Tentang Perlindungan bagi Pendidik dan Tenaga Kependidikan (Nomor 356).

Presiden Republik Indonesia. (2016). Instruksi Presiden Nomor 9 Tahun 2016 tentang Revitalisasi SMK dalam rangka Peningkatan Kualitas dan Daya Saing SDM Indonesia (hal. $1-10)$.
Siswantari. (2015). Pengembangan Program Studi Keahlian Pada Smk Sesuai Kegiatan Ekonomi Unggulan Daerah. Jurnal Pendidikan dan Kebudayaan, Vol. 21, Nomor 2, Agustus 2015, 21, 135-152.

Suryadi, Ace. 2010. Permasalahan dan Alternatif Kebijakan Peningkatan Relevansi Pendidikan 